


\title{
Mass spectrometric analysis of imidazolium-based ionic liquids by scanning atom probe
}

\author{
A. Tolstogouzov ${ }^{\mathrm{a}, *}$, U. Bardi $^{\mathrm{a}}$, O. Nishikawa $^{\mathrm{b}}$, M. Taniguchi $^{\mathrm{b}}$ \\ a Department of Chemistry, University of Florence, via della Lastruccia 3, 50019 Sesto Fiorentino (FI), Italy \\ ${ }^{\mathrm{b}}$ Department of Chemistry and Biology, Kanazawa Institute of Technology, 7-1 Ohgigaoka, Nonoichi 921-850, Japan
}

\section{A R T I C L E I N F O}

\section{Article history:}

Received 28 October 2008

Received in revised form

26 November 2008

Accepted 27 November 2008

Available online 3 December 2008

Partially presented by O. Nishikawa at the 9th International Conference on Atomically Controlled Surfaces, Interfaces and Nanostructures, Tokyo (Japan), 11-15 November 2007

\section{Keywords:}

Ionic liquids

High voltage field evaporation

Photon-assisted field evaporation

Scanning atom probe

\begin{abstract}
A B S T R A C T
Scanning atom probe was used for studying several imidazolium-based ionic liquids of the form $[\mathrm{R}]\left[\mathrm{Tf}_{2}\right.$ where [R] can be one of the three cations-[emim], [bmim] and [hmim]. High voltage pulsing caused formation of the product ions via cations and anion decomposition. Laser pulsing (photon-assisted fi evaporation) allowed generating the intact cation ions along with cluster ions composed of cations a fragments of anion.
\end{abstract}

(C) 2008 Elsevier B.V. All rights reserv

\section{Introduction}

Thermionic and field ion emission from electrolytes is a topic of interest (see, e.g. [1,2]) with numerous compounds, both solid and liquid, being studied. The long term objective of these studies is the development of bright and fine focusable ion beam sources for applications in ion lithography [3], materials analysis, and space propulsion [4].

Room temperature ionic liquids (ILs)-molten salts characterized by melting point below $100^{\circ} \mathrm{C}$-hold much promise for the production of new chemical and extractive processes, fuel cells and batteries, and new composite materials [5-7]. ILs are composed of ions, not of neutral molecules as common liquids; therefore, they can be used for the direct production of ion beams. Very recently, bipolar ionic liquid ion source operated with different ionic liquids has been developed $[8,9]$.

In the present work, we report on the time-of-flight (ToF) mass spectrometric studying of 1-alkyl-3-methylimidazolium

\footnotetext{
* Corresponding author. Tel.: +39 055457 3116; fax: +39 0554573120 . E-mail address: alexander.tolstoguzov@unifi.it (A. Tolstogouzov).
}

bis(trifluoromethylsufonyl)imide salts (where alkyl-ethyl, bu and hexyl) by the scanning atom probe (SAP) developed Nishikawa [10,11]. Both high voltage (electrical) and laser (photc pulsing was applied for field evaporation/ionization of ionic liqu from the surface of an electrochemically etched tungsten tip.

\section{Experimental}

We used commercially available imidazolium-based ios liquids obtained from Merck KGaA [12]. Table 1 shows the appel tions/abbreviations, structures, formulas and molecular weights the liquids used. All the compounds are hydrophobic room temp ature molten salts with conductivity better than $1 \mathrm{~S} \mathrm{~m}^{-1}$. Detail information about imidazolium-based ionic liquids can be found Ref. [13]. The liquids were used in our experiments without ad tional purification. A few milligrams of the IL were placed on etched tungsten tip, which was mounted in the vacuum chamb $\left(10^{-6} \mathrm{~Pa}\right)$ close to the centre of the open hole of a scanning electro

The structure of our system and details of the SAP measu ments have been reported elsewhere $[9,10]$. In brief, the SAP syst is equipped with a miniature electrode made of a Pt foil, wh localizes the electric field in a small space in the gap betwe 


\begin{tabular}{lll}
\hline Appellation abbreviation & Formula molecular weight $(D)$ & Cation molecular weight $(D)$ \\
$\begin{array}{l}\text { 1-Ethyl-3-methylimidazolium } \\
\text { bis(trifluoromethylsufonyl)imide } \\
\text { [emim][Tf } 2 \mathrm{~N}]\end{array}$ & $\mathrm{C}_{8} \mathrm{H}_{11} \mathrm{~N}_{3} \mathrm{O}_{4} \mathrm{~S}_{2} \mathrm{~F}_{6} ; 391.31$
\end{tabular}

the specimen and the electrode. In order to trigger field evaporation, voltage pulses of $2 \mathrm{~ns}$ rise time or laser pulses of $5 \mathrm{~ns}$ width at $\lambda=532 \mathrm{~nm}$ (the $2 \mathrm{nd}$ harmonics of Nd:YAG) were used. Typical power of the laser pulses were $1 \mathrm{~mJ}$ per shot. The evaporated ions were analysed by a ToF analyser of the reflectron type with the mass resolution, $M / \Delta M$, higher than 1000 (FWHM).

\section{Results and discussion}

In Figs. 1-3, we show the mass spectra of the positive ions measured for the different ionic liquids via high voltage pulsing (HVP) and with laser pulsing (LP). The HVP mass spectra (designated in the panels by a letter "a") are all similar, despite the fact that cations contain different alkyl groups. Neither parent molecular ions nor
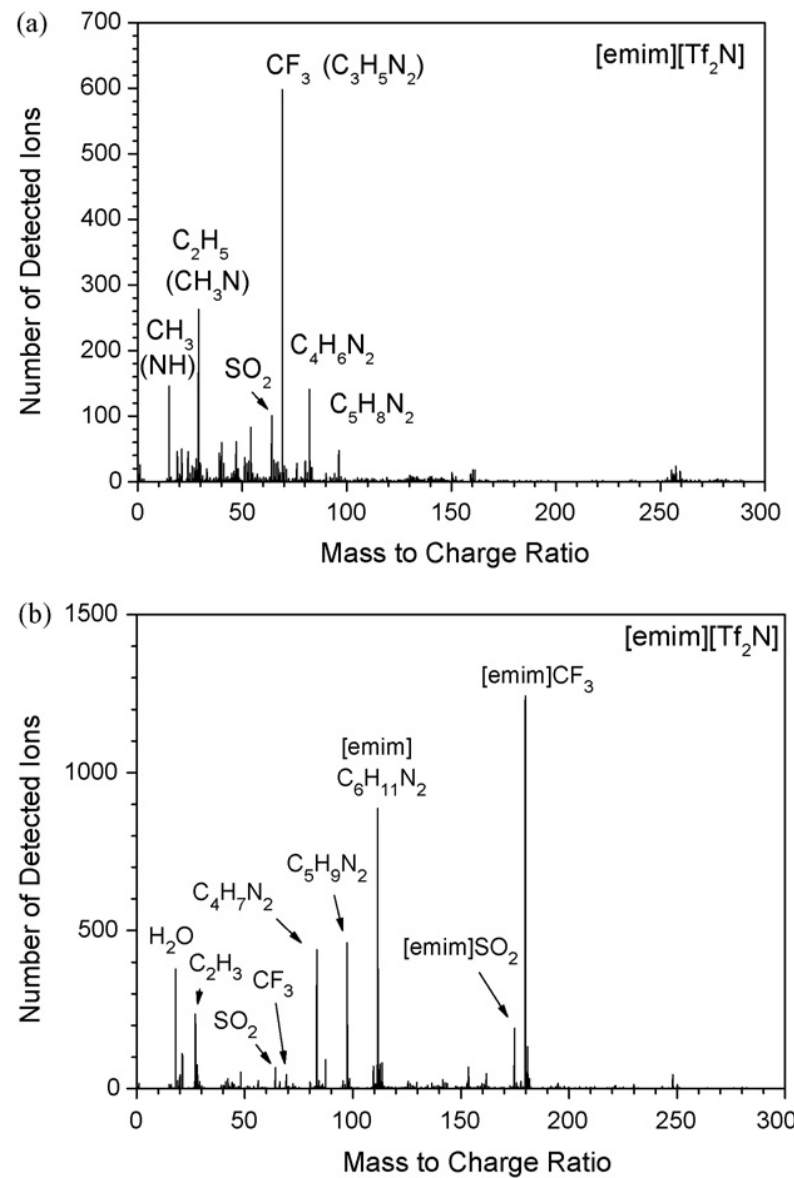

Fig. 1. Mass spectra of the positive ions measured for the [emim] $\left[\mathrm{Tf}_{2} \mathrm{~N}\right]$ samples with high voltage (a) and with laser (b) pulsing. intact cation/anion peaks were observed in our experiments with electrical pulsing. The dominant peak of $m / z 69$ can be assigned to $\left[\mathrm{CF}_{3}\right]^{+}$and/or $\left[\mathrm{C}_{3} \mathrm{H}_{5} \mathrm{~N}_{2}\right]^{+}$ions originating from the anion and cation parts of the IL, respectively. Most likely that these ions are anion decomposition products, together with $\left[\mathrm{SO}^{+}\right.$and $\left[\mathrm{SO}_{2}\right]^{+}$, and some low intense ion species in the range of $m / z$ 130-160 and $m / z 250-265$. The electron-ionization mass spectra collected in our previous studying of imidazolium-based ionic liquids with Knudsen effusion mass spectrometry [14] did not show the presence of $\left[\mathrm{Tf}_{2} \mathrm{~N}\right]^{+}$ions, either.

Other less intense peaks shown in Figs. 1(a)-3(a) can be attributed to degradation products of the parent cations. Among them, we observed $\left[\mathrm{C}_{5} \mathrm{H}_{8(9)} \mathrm{N}_{2}\right]^{+}$and $\left[\mathrm{C}_{4} \mathrm{H}_{6(7)} \mathrm{N}_{2}\right]^{+}$formed via
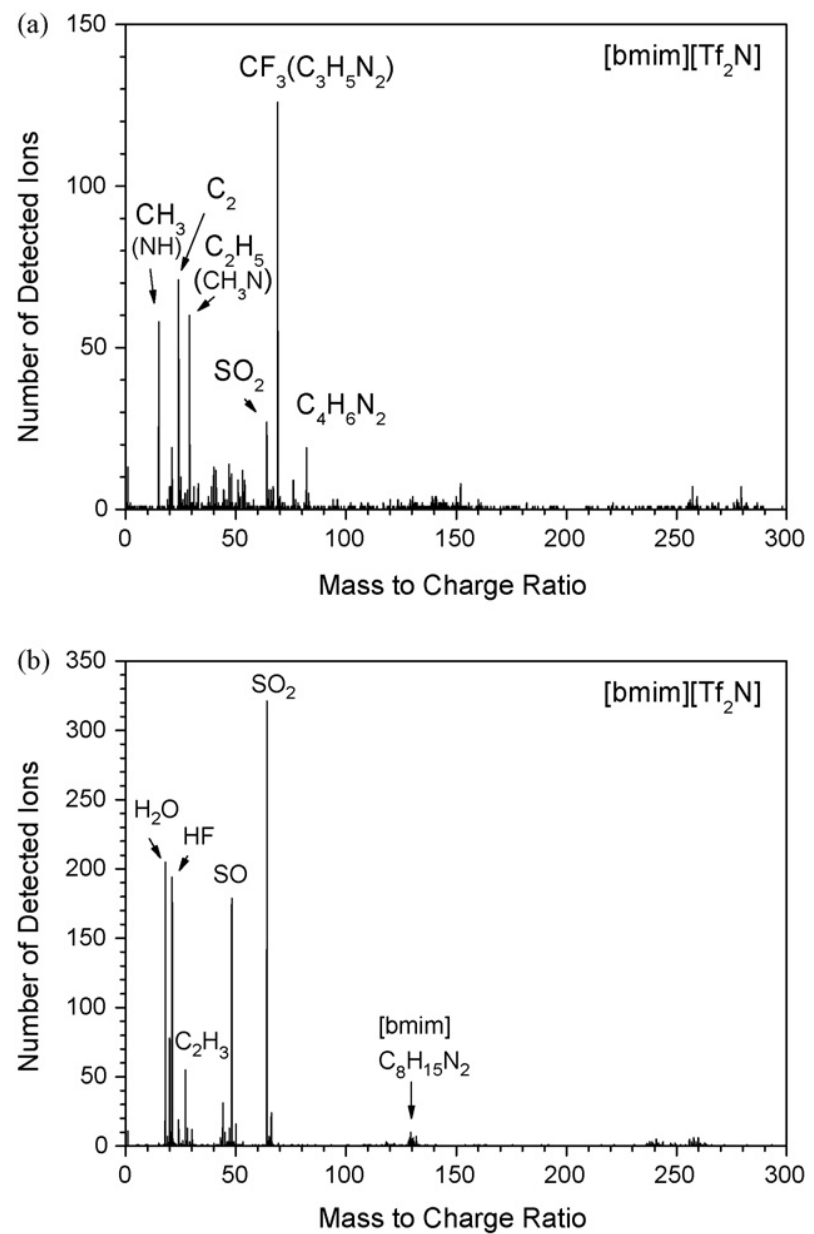

Fig. 2. Mass spectra of the positive ions measured for the $[b m i m]\left[\mathrm{Tf}_{2} \mathrm{~N}\right]$ samples with high voltage (a) and with laser (b) pulsing. 

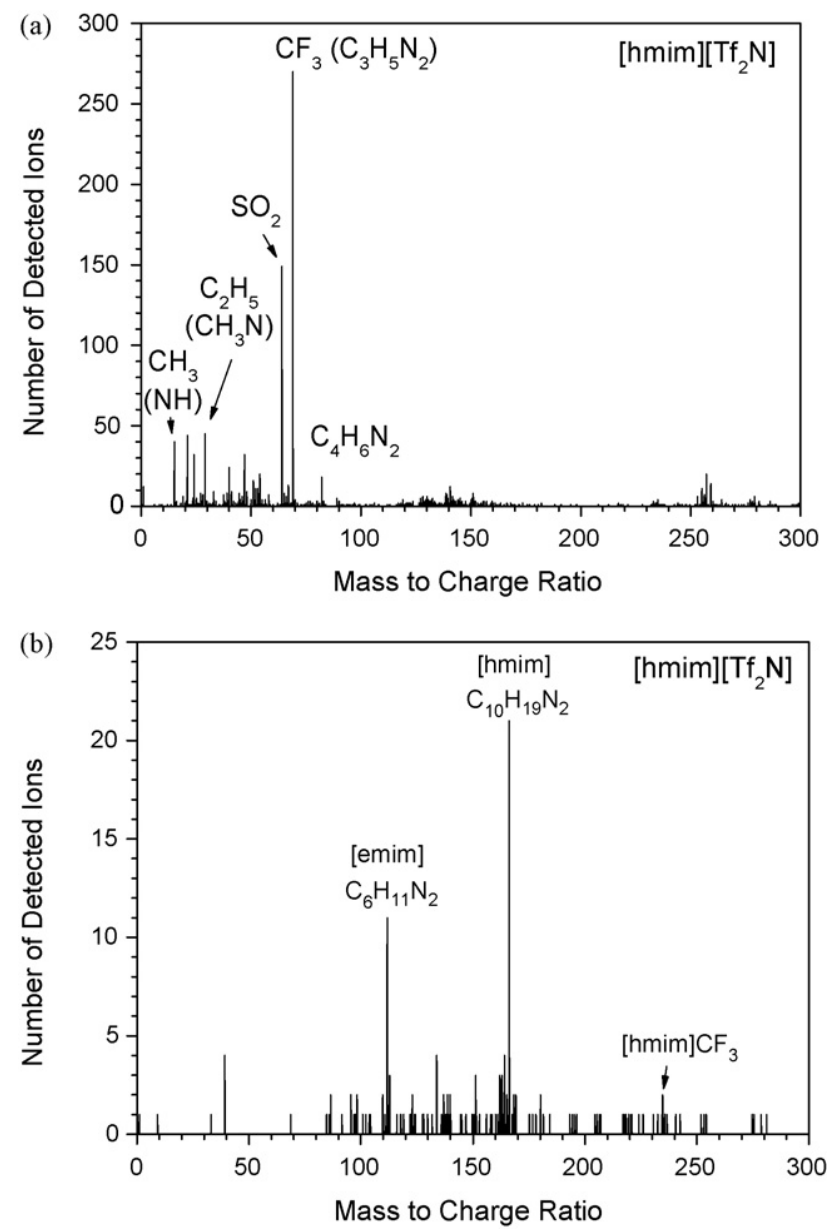

Fig. 3. Mass spectra of the positive ions measured for the [hmim][Tf $2 \mathrm{~N}]$ samples with high voltage (a) and with laser (b) pulsing.

breaking the $\mathrm{N}-\mathrm{C}$ bonds with a loss of methyl groups. This process can be the result of the transfer of a hydrogen atom to the residual nitrogen group. The peaks of $m / z 29\left(\left[\mathrm{C}_{2} \mathrm{H}_{5}\right]^{+}\right.$and $\left.\left[\mathrm{CH}_{3} \mathrm{~N}\right]^{+}\right)$and $m / z 15\left(\left[\mathrm{CH}_{3}\right]^{+}\right.$and $\left.[\mathrm{NH}]^{+}\right)$are the fragments of the cations as well.

The LP spectra presented in Figs. 1(b)-3(b) differ from the HVP spectra discussed above. With laser pulsing we observed not only the product ions, but also the peaks related to the non-degraded cations and some complex (cluster) ions composed of the intact cations and anion fragments such as $\mathrm{CF}_{3}$ and $\mathrm{SO}_{2}$. Both cations and complex ions peaks are observed together with the peaks related to the ${ }^{13} \mathrm{C}$ isotope. Intense spectra were measured for the [emim] $\left[\mathrm{Tf}_{2} \mathrm{~N}\right]$ sample (Fig. 1(b)); the total number of the detected ions was close to $10^{4}$. This result was predictable because for 1alkyl-3-methylimidazolium bis(trifluoromethylsufonyl)imide salts an increase in the mass (or in the length) of alkyl chain leads to the increasing of viscosity, namely from $26.13 \mathrm{~mm}^{2} \mathrm{~s}^{-1}$ for ethyl to $44.02 \mathrm{~mm}^{2} \mathrm{~s}^{-1}$ for hexyl groups at room temperature [12]. Therefore, [emim] $\left[\mathrm{Tf}_{2} \mathrm{~N}\right]$, the most lightweight salt amongst the ILs studied, shows the best wetting of an emitting tungsten tip and also provides the largest ion current.

Less intense mass spectra with a dominant peak corresponding to the intact cation $\left[\mathrm{C}_{10} \mathrm{H}_{19} \mathrm{~N}_{2}\right]^{+}(\mathrm{m} / \mathrm{z}$ 167) and a noise-level peak for $[\mathrm{hmim}] \mathrm{CF}_{3}{ }^{+}$clusters were collected for $[\mathrm{hmim}]\left[\mathrm{Tf}_{2} \mathrm{~N}\right]$ (Fig. 3(b)). We did not observe well-defined spectra for the [bmim] $\left[\mathrm{Tf}_{2} \mathrm{~N}\right]$ sample with laser pulsing. Only a small peak for the $\left[\mathrm{C}_{8} \mathrm{H}_{15} \mathrm{~N}_{2}\right]^{+}$cation of $m / z 139$ was registered (Fig. 2(b)). We observed, instead, intense peaks for anion degradation products such like $\left[\mathrm{SO}_{2}\right]^{+},[\mathrm{SO}]^{+},[\mathrm{HF}]^{+}$, and $\left[\mathrm{H}_{2} \mathrm{O}\right]^{+}$. The $[\mathrm{bmim}]\left[\mathrm{Tf}_{2} \mathrm{~N}\right]$ ionic liquid might have been contaminated by water during storing or in the course of sample preparation. That would result in the $s$ vation of the IL components, both cation and anion parts, a cause uncontrolled modification of conductivity, viscosity, a other chemical-physical properties.

Recently, Lozano and Martínez-Sánchez [15] have shown tl the extraction of only polarity ions causes the electrochemi decomposition of the ionic liquid, as it was observed for a tungst wire field emitter wetted with [emim] $\left[\mathrm{BF}_{4}\right]$. In order to suppr this detrimental effect, they varied the voltage source polarity, frc positive to negative and vice versa, at $1 \mathrm{~Hz}$ frequency. Curren such regime is not obtainable in our instrument, and the volta applying to the tip is always positive relative to the grounded sca ning electrode. Thus, while cations move towards the liquid surfa and then are extracted by electric field in vacuum, the negative ic from $\left[\mathrm{Tf}_{2} \mathrm{~N}\right]$ moiety stay in the IL and eventually discharge at $\mathrm{t}$ surface of a tungsten tip. The remaining neutralized molecules a radicals can accumulate in ionic liquid and react with tungsten th finally induce degradation of the liquid, the emitter or both. A consequence, steady-state mass spectra of the positively charg ions obtained via high voltage pulsing (Figs. 1(a)-3(a)) look ve similar for all ILs studied; these spectra contain mainly fragme ions, practically without evident contribution of parent cations.

It is known that photon-assisted field evaporation offers advantage as compared with the more commonly used HVP regin This is due to the rapid thermal activation of the emitting surfa [16,17]. Also, laser irradiation can produce direct photo-ionizatic if the photon energy is high enough for that. Ultrashort laser puls in the picosecond range, are able to stimulate field evaporation supplying the vibration energy for climbing up the surface en getic barrier, whose height is lowered by the application of hi electric field [18].

In our LP experiments, the photon energy (ca. $2.3 \mathrm{eV}$ ) and $\mathrm{t}$ duration of the laser pulses ( $5 \mathrm{~ns}$ ) are insufficient for obtaining t two last emission mechanisms. However, as it has been shown our previous work [14] with Knudsen effusion mass spectromet the peaks of the intact cations are the most intense mass spec via thermal evaporation of the same imidazolium-based ILs. We $c$ assume, therefore, that under laser pulsing ionic liquids evapor: by a fast thermal mechanism in the form of the parent molecul Then, photon-assisted field dissociation follows that generates p itively charged cations and negatively charged anions. It is lik that such dissociation process can also occur directly onto surface of ionic liquids and that it would be followed by field eva oration of positively charged cations, their fragments and comp. ions being composed of cations and anion fragments. As shown Ding et al. [19], laser excitation is able of performing desorpti and ionization of surface molecules from a clean $\operatorname{Si}\left(\begin{array}{lll}1 & 1 & 1\end{array}\right)$ sam solely via the optical near field enhancement in the proximity 0 scanning tunnelling microscope tip. That is possible without use any other external stimulus. The authors of this publication us more short-wave and short-pulse laser system (Nd:YAG, $266 \mathrm{n}$ $100 \mathrm{ps}$ ), however, sublimation energy, melting point and ionizati energy of silicon are considerably higher than similar character tics of ionic liquids. The situation with degradation of ionic liqu under laser pulsing is not clear at this moment. From mass spec presented in Figs. 1(b)-3(b) it is evident that ILs degradation s exist, however, it is not totally dominating process as in the case high voltage pulsing.

\section{Summary}

Field evaporation of imidazolium-based ionic liquids with sca ning atom probe is shown that mass spectra of the positiv charged ions obtained via high voltage pulsing are very similar all ILs studied; the spectra show only cation and anion fragme probably due to the prevalent electrochemical decomposition of $t$ 
liquids stimulated by extraction only single polarity ions. On the contrary, the spectra measured under laser pulsing exhibit intense peaks corresponding to the initial cations along with clusters composed of cations and anion fragments. There is a good reason to believe that laser irradiation in the nanosecond time-scale promotes the sublimation of parent molecules by means of the fast thermal activation of emitting surface. In that case, electric field evaporation of ionic liquids with laser stimulation looks as a potentially promising avenue for the developing of high brightness ion beam sources of positively and negatively charged molecular ions for nanoscale surface modification, materials microanalysis, and for application in space missions as advanced electrostatic thrusters.

\section{Acknowledgement}

This work was supported by the Japan Society for Promotion of Science (JSPS) and by the Italian Interuniversity Consortium on Materials Science and Technology.

\section{References}

[1] C. Escher, S. Thomann, C. Andreoli, H.-W. Fink, J. Toquant, D. Pohl, Appl. Phys. Lett. 89 (2006) 053513.
[2] M. Nishioka, N. Nanjyo, S. Hamakawa, K. Kobayashi, K. Sato, T. Inoue, F. Mizukami, M. Sadacata, Solid State Ionics 117 (2006) 2235.

[3] L. Bischoff, Nucl. Instrum. Meth. B 266 (2008) 1846.

[4] F.G. Rüdenauer, Surf. Interface Anal. 39 (2007) 116.

[5] P. Wasserscheid, T. Welton (Eds.), Ionic Liquids in Synthesis, Wiley-VCH, Weinheim, 2003.

[6] M. Koel, Crit. Rev. Anal. Chem. 35 (2005) 177.

[7] R.D. Rogers, G.A. Voth, Acc. Chem. Res. 40 (2007) 1077.

[8] P.C. Lozano, J. Phys. D: Appl. Phys. 39 (2006) 126.

[9] C. Larriba, S. Castro, J. Fernandez de la Mora, P. Lozano, J. Appl. Phys. 101 (2007) 084303.

[10] O. Nishikawa, K. Maeda, Y. Ohtani, M. Watanabe, K. Tanaka, T. Sekine, M. Iwatsuki, S. Aoki, J. Itoh, Y. Yamanaka, Appl. Surf. Sci. 146 (1999) 398.

[11] O. Nishikawa, Y. Ohtani, K. Maeda, M. Watanabe, K. Tanaka, Mater. Charact. 44 (2000) 29.

[12] http://www.ionicliquids-merck.de, 2008.

[13] C.P. Fredlake, J.M. Crosthwaite, D.G. Hert, S.N.V.K. Aki, J.F. Brennecke, J. Chem. Eng. Data 49 (2004) 954

[14] A. Tolstogouzov, U. Bardi, O. Nishikawa, M. Taniguchi, Surf. Interface Anal. 40 (2008) 1614.

[15] P. Lozano, M. Martínez-Sánchez, J. Colloid Interface Sci. 280 (2004) 149.

[16] T.T. Tsong, Surf. Sci. 70 (1978) 211.

[17] O. Nishikawa, M. Taniguchi, S. Watanabe, A. Yamagishi, T. Sasaki, Jpn. J. Appl. Phys. 45 (2006) 1892.

[18] B. Gault, F. Vurpillot, A. Bostel, A. Menand, B. Deconihout, Appl. Phys. Lett. 86 (2005) 094101

[19] Y. Ding, R. Micheletto, S. Okazaki, K. Otsuka, Appl. Surf. Sci. 211 (2003) 82. 